\title{
Compliance With Mobile Ecological Momentary Assessment of Self-Reported Health-Related Behaviors and Psychological Constructs in Adults: Systematic Review and Meta-analysis
}

\author{
Marie T Williams ${ }^{1 *}$, BAppSc, PhD; Hayley Lewthwaite ${ }^{1,2^{*}}$, BAppSc, BHlthScHons, PhD; François Fraysse ${ }^{3}, \mathrm{PhD}$; \\ Alexandra Gajewska ${ }^{3}$, BClinExPhys, BAHons, Dip Ed; Jordan Ignatavicius ${ }^{3}$, BPhysio; Katia Ferrar ${ }^{3 *}$, BAppSc, \\ BHlthScHons, $\mathrm{PhD}$

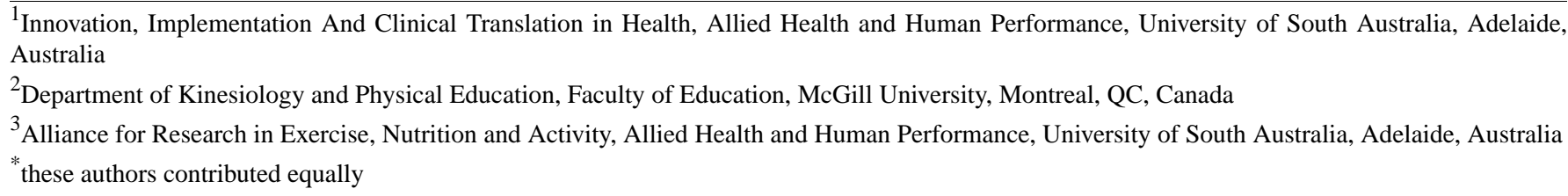

Corresponding Author:

Marie T Williams, BAppSc, PhD

Innovation, Implementation And Clinical Translation in Health

Allied Health and Human Performance

University of South Australia

City East Campus, North Terrace

Adelaide, 5000

Australia

Phone: 61883021153

Email: Marie.Williams@unisa.edu.au

\begin{abstract}
Background: Mobile ecological momentary assessment (mEMA) permits real-time capture of self-reported participant behaviors and perceptual experiences. Reporting of mEMA protocols and compliance has been identified as problematic within systematic reviews of children, youth, and specific clinical populations of adults.

Objective: This study aimed to describe the use of mEMA for self-reported behaviors and psychological constructs, mEMA protocol and compliance reporting, and associations between key components of mEMA protocols and compliance in studies of nonclinical and clinical samples of adults.

Methods: In total, 9 electronic databases were searched (2006-2016) for observational studies reporting compliance to mEMA for health-related data from adults ( $>18$ years) in nonclinical and clinical settings. Screening and data extraction were undertaken by independent reviewers, with discrepancies resolved by consensus. Narrative synthesis described participants, mEMA target, protocol, and compliance. Random effects meta-analysis explored factors associated with cohort compliance (monitoring duration, daily prompt frequency or schedule, device type, training, incentives, and burden score). Random effects analysis of variance $(P \leq .05)$ assessed differences between nonclinical and clinical data sets.
\end{abstract}

Results: Of the 168 eligible studies, 97/105 (57.7\%) reported compliance in unique data sets (nonclinical=64/105 [61\%], clinical=41/105 [39\%]). The most common self-reported mEMA target was affect (primary target: $31 / 105$, 29.5\% data sets; secondary target: 50/105, 47.6\% data sets). The median duration of the mEMA protocol was 7 days (nonclinical=7, clinical=12). Most protocols used a single time-based (random or interval) prompt type $(69 / 105,65.7 \%)$; median prompt frequency was 5 per day. The median number of items per prompt was similar for nonclinical (8) and clinical data sets (10). More than half of the data sets reported mEMA training $(84 / 105,80 \%)$ and provision of participant incentives $(66 / 105,62.9 \%)$. Less than half of the data sets reported number of prompts delivered $(22 / 105,21 \%)$, answered $(43 / 105,41 \%)$, criterion for valid mEMA data $(37 / 105$, $35.2 \%$ ), or response latency $(38 / 105,36.2 \%)$. Meta-analysis (nonclinical=41, clinical=27) estimated an overall compliance of 81.9\% (95\% CI 79.1-84.4), with no significant difference between nonclinical and clinical data sets or estimates before or after data exclusions. Compliance was associated with prompts per day and items per prompt for nonclinical data sets. Although 
widespread heterogeneity existed across analysis $\left(\mathrm{I}^{2}>90 \%\right)$, no compelling relationship was identified between key features of mEMA protocols representing burden and mEMA compliance.

Conclusions: In this 10-year sample of studies using the mEMA of self-reported health-related behaviors and psychological constructs in adult nonclinical and clinical populations, mEMA was applied across contexts and health conditions and to collect a range of health-related data. There was inconsistent reporting of compliance and key features within protocols, which limited the ability to confidently identify components of mEMA schedules likely to have a specific impact on compliance.

(J Med Internet Res 2021;23(3):e17023) doi: $\underline{10.2196 / 17023}$

\section{KEYWORDS}

mobile momentary ecological assessment; adult; compliance; systematic review; meta-analysis; mobile phone

\section{Introduction}

\section{Background}

Ecological momentary assessment (EMA) is a survey method that allows collection of data on participant behaviors, affect, and perceptual experiences in real-time (momentary) and real-life environments (ecological) [1]. In its original form, EMA required pen and paper diaries or logs to be completed on random (signal) or fixed (interval) time-based schedules or in response to a specific target behavior, psychological or social event (event-based). With the advent of handheld technologies, mobile EMA (mEMA) and increasingly mobile ecological momentary interventions (mEMIs) can be completed through automated schedules via handheld devices such as tablets and mobile phones.

As mEMA or mEMI have the potential to capture data in real time, the level of recall bias is potentially reduced. In addition, contextual (where and who the respondent is with) and antecedents to the specific target behavior or psychological construct can be obtained [1,2]. As a survey approach, mEMA or mEMI has undeniable utility, but data are dependent on participants consistently responding to the mEMA or mEMI schedule (compliance) [3]. Although electronically delivered surveys to personal mobile devices provide a means of time or date stamping and limit the possibility of hoarding, back and forward filling [4], concerns have been raised about protocol burden, missing data (especially if systematic), mindless answering, and survey habituation when lengthier questionnaires can be circumvented by a no response to initial questions [2]. EMA data with low compliance rates are unlikely to be ecologically valid; however, it is also possible to have good individual compliance with data of questionable accuracy $[5,6]$.

In the last 5 years, there have been at least 10 systematic reviews focused on EMA and/or reporting aspects of compliance to EMA schedules in youth $(<18$ years [7-9]; $<22$ years [10]), mixed youth and adult cohorts [11-13], or specific adult populations [5,14-16]. Compliance with EMA in youth (nonclinical and clinical samples) has been reported to range between $44 \%$ and $96 \%$ [8-10] and in mixed youth and adult cohorts, between $23 \%$ and 94\% [11-14]. Reports of compliance in specific adult clinical populations range from $21 \%$ to $99 \%$ (chronic pain, 21\%-99\% [15]; psychotic disorders, 78\%-86\% [16]; substance use, 75\%, (95\% CI 72.37-77.65) [5].

Although Stone and Shiffman [17] have highlighted the need for explicit reporting of compliance in their original reporting guidelines for EMA, recurring issues relating to the reporting of compliance include (1) missing, incomplete, or ambiguous data; (2) heterogeneity in reporting; (3) impact of data exclusions; and (4) combining traditional (paper-based) and mEMA data [5]. Participant compliance with mEMA or mEMI - in theory - is related to the total protocol burden, which is a function of monitoring duration, frequency and complexity of prompts, and familiarity with the technology. However, as Jones et al [5] note, to date, there is little compelling, systematic evidence to support an association between EMA burden and compliance rates. These issues make it difficult to determine which, if any, features of EMA protocols positively or negatively influence compliance to EMA schedules.

The purpose of this systematic review is to guide the development of an mEMA protocol, which could be used for future studies of health-related behaviors and psychological constructs (including symptoms) in adults with and without chronic disease. The primary question for this systematic review is as follows: In adult nonclinical and clinical populations, which factors are associated with increased compliance to mEMA protocols for collection of health-related behaviors and psychological constructs (including symptoms)?

\section{Objectives}

The objectives of this systematic review were to describe:

1. Health-related behaviors and psychological constructs assessed using mEMA

2. mEMA protocol and compliance reporting

3. Associations between key components of mEMA protocols and participant compliance

\section{Methods}

\section{Search Registration}

The search strategy and review protocol were registered prospectively with the International Prospective Register of Systematic Reviews (PROSPERO 2016: CRD42016051726).

\section{Eligibility}

Observational studies (cohort, cross-sectional) of mEMA in adults (>18 years of age) were eligible for inclusion in this review if these (1) reported participant compliance with mEMA; (2) were a primary study published in English between 2006 and 2016 inclusive; (3) included adults ( $\geq 18$ years) either apparently healthy (nonclinical population) or with health conditions (clinical population); and (4) collected mEMA data 
using mobile devices as a primary or secondary outcome. References were excluded if these were (1) experimental designs investigating intervention efficacy; (2) duplicate publications or secondary analysis of the same data set; or (3) conference abstracts, protocols, commentaries (editorials or letters), or systematic or narrative reviews.

\section{Information Sources and Search Strategy}

A range of electronic databases were searched to identify eligible studies: AMED (Allied and Complementary Medicine), CINAHL, Cochrane Library and CENTRAL (Cochrane Central Register of Controlled Trials), Embase, MEDLINE (including epub ahead of print), PsycINFO, Scopus, and Web of Science. An academic librarian (Carole Gibbs, University of South Australia) assisted with the development of the search strategy regarding conceptualization, operators (operational terms), and limiters [18] with the final search undertaken during a single week. Search terms and associated MeSH (Medical Subject Heading) alternatives, which were adapted for use in all databases, related to the population (adults), assessment (mEMA), and outcomes of interest (health behaviors, perceptual experiences including symptoms, affect or mood). Key search terms included "ecological momentary assessment," "EMA," "mobile ecological momentary assessment," "mEMA," "electronic diary," "SMS or short message service," "prompting," "text messaging," "health behaviour," "symptom," and "adult." Reference lists of included studies and systematic reviews identified during the search were reviewed to identify additional potentially relevant studies.

\section{Study Selection}

The titles and abstracts of studies identified from the search process were screened against a priori eligibility criteria and full-text versions imported into Covidence (Covidence systematic review software, Veritas Health Innovation). Both screening steps were undertaken by individual members of the research team working in pairs (AG and MW, HL and FF) with each person completing the task independently, before meeting with their partner to compare results and resolve disagreements (consensus).

\section{Data Collection}

A data extraction template was prospectively developed; it was guided by the Checklist for Reporting EMA studies proposed by Liao et al [10] and pilot-tested on 5 randomly selected eligible studies. Working in pairs (AG and MW, JI and KF, HL and FF), individual members of the research team extracted all data before meeting with their partner to compare results and resolve disagreements by discussion. As this review aims to describe the features of mEMA schedules associated with increased mEMA protocol adherence, assessment of methodological bias was not planned.

\section{Data Items}

Data were extracted across 4 domains:

Publication demographics: title, authors, year of publication.

Participants: recruitment source, medical condition or diagnosis (clinical populations), sample size (enrolled, attrition or withdrawn and included in analysis), and age (mean/median, $\mathrm{SD})$.

mEMA protocol: target behavior or psychological construct, mobile device type (PDA, palmtop computer, electronic diary, mobile or smartphone, tablet, other), participant training (yes/no), provision of incentives (course credit, financial, other, or none), incentive thresholds (yes/no) monitoring duration (days), prompt type (random signal, interval, event-based), frequency per day, number of questions/items per prompt type (reported or estimated from information reported in studies), strategy to deal with unanswered prompts, and time allowed for survey response. Where authors did not report the number of items per prompt type, but rather included descriptions of standardized instruments which were converted to mEMA survey items, a full version of the standardized instrument was accessed, and number of items calculated.

mEMA compliance: verbatim (or where possible calculated from reported data), participant completion (number included in analysis, data exclusions), criteria/thresholds for mEMA data, number of prompts delivered/answered per person/cohort (planned, actual, average, range), and response latency as time (mean, SD) [8,10].

\section{Data Management}

Data were tabulated to provide descriptive summaries. The mEMA surveys commonly included multiple questions reflecting behavioral or psychological constructs. Although the authors of mEMA studies did not always specify the primary outcome for these observational studies, most studies explicitly reported the key variable of interest for mEMA, which we interpreted to be the primary mEMA target. Where other data were also collected by the same mEMA survey, we denoted those as secondary mEMA targets. The primary mEMA target of studies was identified, and studies were grouped and reported according to two broad domains: (1) behavior (eg, dietary, physical activity, and smoking) and (2) psychological construct (eg, affect, cognition, and sensations/symptoms). For each domain, a narrative synthesis was used to summarize participants, mEMA protocol, and compliance data for nonclinical and clinical data sets.

With the exception of device type, where possible, we adopted the operationalization of variables common to Wen et al [9] or Jones et al [5] unless the distribution of our data resulted in very unbalanced cells or our data could provide greater resolution. Potential mEMA protocol factors related to compliance were categorized for analysis. Monitoring duration was categorized as follows: $<7$ days, $>7$ days to $<14$ days, or $>14$ days. Prompt frequency was grouped as follows: 1-3 prompts per day; 4-5 prompts per day; or $\geq 6$ prompts per day. Minimum items per prompt were categorized as follows: $\leq 5,>5$ to $\leq 9.5,>9.5$ to $\leq 26$, and $>26$. Device type was categorized as mobile phone, PalmPilot/PDA, or other. The reporting of training or familiarization sessions or provision of incentives were dichotomized as yes/no or labeled as not reported.

Given ongoing concerns about the burden imposed by EMA schedules and compliance, in addition to these individual factors, we explored a novel composite metric to reflect aspects 
previously identified as possible contributing factors (monitoring duration, frequency, type, and complexity of prompts).

Where possible, a mEMA burden score was calculated for each study by multiplying:

- $\quad$ the total monitoring duration in days (d; all days included in all waves)

- $\quad$ by the maximum frequency of time-based prompts (random and interval) per day (f)

- by the minimum number of compulsory questions/items within all prompts per day (i) and

- by a weighting reflecting the number of prompt types scheduled per day (w; eg, time-based [signal or interval] and/or event-based) with each prompt type weighted as 1 ( $\min$ weight $=1, \max =3$ ).

For example, the mEMA burden score for a 14-day monitoring schedule $(d)$, where 5 random signal prompts were delivered per day $(f)$, with each prompt requiring responses to a minimum of 12 items/questions ( $I ; 60$ items in total per day), would be 840. If event-based prompts (irrespective of the number of items within the prompt) were added to this schedule $(w)$, the burden score would rise to 1680 . Burden scores were calculated and reported in quartiles: 0 to $283.5,284$ to 810,811 to 1806 , or $\geq 1807$.

\section{Meta-analysis}

Random effects restricted maximum likelihood estimator meta-analyses were undertaken using the approach reported by Jones et al [5] and Wen et al [9], with both authors advising to assist in accurate replication. All statistical analyses were conducted using JASP (Jeffreys's Amazing Statistics Program, version $0.9 .2 ; 2019)$. Studies were included in the meta-analysis if they reported all data necessary for the meta-analysis procedure and cohort compliance $(\%)$ could be extracted before data exclusions when possible. Sensitivity analysis was conducted to explore the impact of compliance rates reported before and after data exclusion. The effect sizes (ESs) were calculated by logit transforming the proportion of completed prompts (ie, compliance rates; proportion/[1-proportion]). SEs were then estimated using the following equation:

$$
\sqrt{ }([1 / n p]+[1 / n\{1-p\}])
$$

Where, $n$ is the sample size and $p$ is the proportion.

To adjust for clustering within participants, the SE was adjusted by the effective sample size (ESS). The ESS equation is as follows:

$$
\mathrm{kn} /(1+[\mathrm{k}-1] \mathrm{ICC})
$$

Where, $\mathrm{k}$ is the number of study prompts, $\mathrm{n}$ is the participant number, ICC is either the reported intraclass correlation coefficient (ICC) or the SD of reported compliance, and $\mathrm{p}$ is the proportion of completed prompts.
For studies that did not report SD data, sensitivity analyses were conducted by computing the SEs using the 25 and 75 percentiles of available SDs. The sensitivity analyses did not show any differences. Therefore, analysis used imputed median SD (where the original SD was not reported). To aid interpretation, inverse logit transformation was conducted to enable reporting of proportions. The $\mathrm{I}^{2}$ statistic was used to quantify heterogeneity across the ES. Pooled compliance rates were initially explored for combined nonclinical and clinical data sets and then compared between nonclinical and clinical studies.

To explore the relationships between the pooled compliance rates (nonclinical and clinical data sets) and EMA protocol factors (ie, monitoring duration, prompt frequency, device type, training, incentives, and burden score), random effects analysis of variance was conducted as part of the meta-analysis program. Moderator analyses were conducted separately for nonclinical and clinical pooled compliance.

\section{Results}

\section{Overview}

Figure 1 presents the outcome of the search strategy. Of the 282 studies reviewed as full text, 168/282 (59.6\%) included mEMA; however, $42.3 \%(71 / 168)$ were excluded because mEMA compliance was not reported. The majority of the 97 studies retained for this review comprised studies that recruited or reported a single nonclinical group $(61 / 97,63 \%)$ or a clinical $(31 / 97,32 \%)$ group. Two studies included 2 [19] or 3 clinical groups [20]. In addition, 3 studies included clinical and nonclinical comparator groups (4 groups [21], 2 groups [22,23]). Overall, 105 data sets were included in this review (nonclinical: 64/105, 61\%; clinical: 41/105, 39\%). A description of all included data sets is presented in Multimedia Appendix 1 [19-114].

A total of 44,796 participants were included in the analyses (nonclinical: 42,338/44,796, 94.51\%; clinical: 2431/44,796, $5.43 \%$ ) with a median sample size of 62 (nonclinical: $n=89$; clinical: $n=40 ;$ Multimedia Appendix 2). Two data sets (nonclinical) were outliers because of the sample size ( $n=21,947$; $n=11,572)[24,25]$. The main sources of recruitment for nonclinical data sets were educational institutions (30/64, 47\%) and community $(26 / 64,41 \%)$, whereas clinical data sets were predominantly recruited from medical/health services $(21 / 41$, $51 \%$ ) and community $(17 / 41,41 \%)$. For clinical data sets, the most common health conditions were psychiatric or mental health $(12 / 41,29 \%)$, chronic pain and fibromyalgia $(6 / 41,15 \%)$, and eating disorders $(5 / 41,12 \%)$. Multimedia Appendix 2 presents a summary of the study characteristics grouped by primary mEMA target. 
Figure 1. Search strategy process and final outcomes (hand searching of reference list-eligible studies and review papers did not identify additional studies to those returned by database searches). mEMA: mobile ecological momentary assessment.

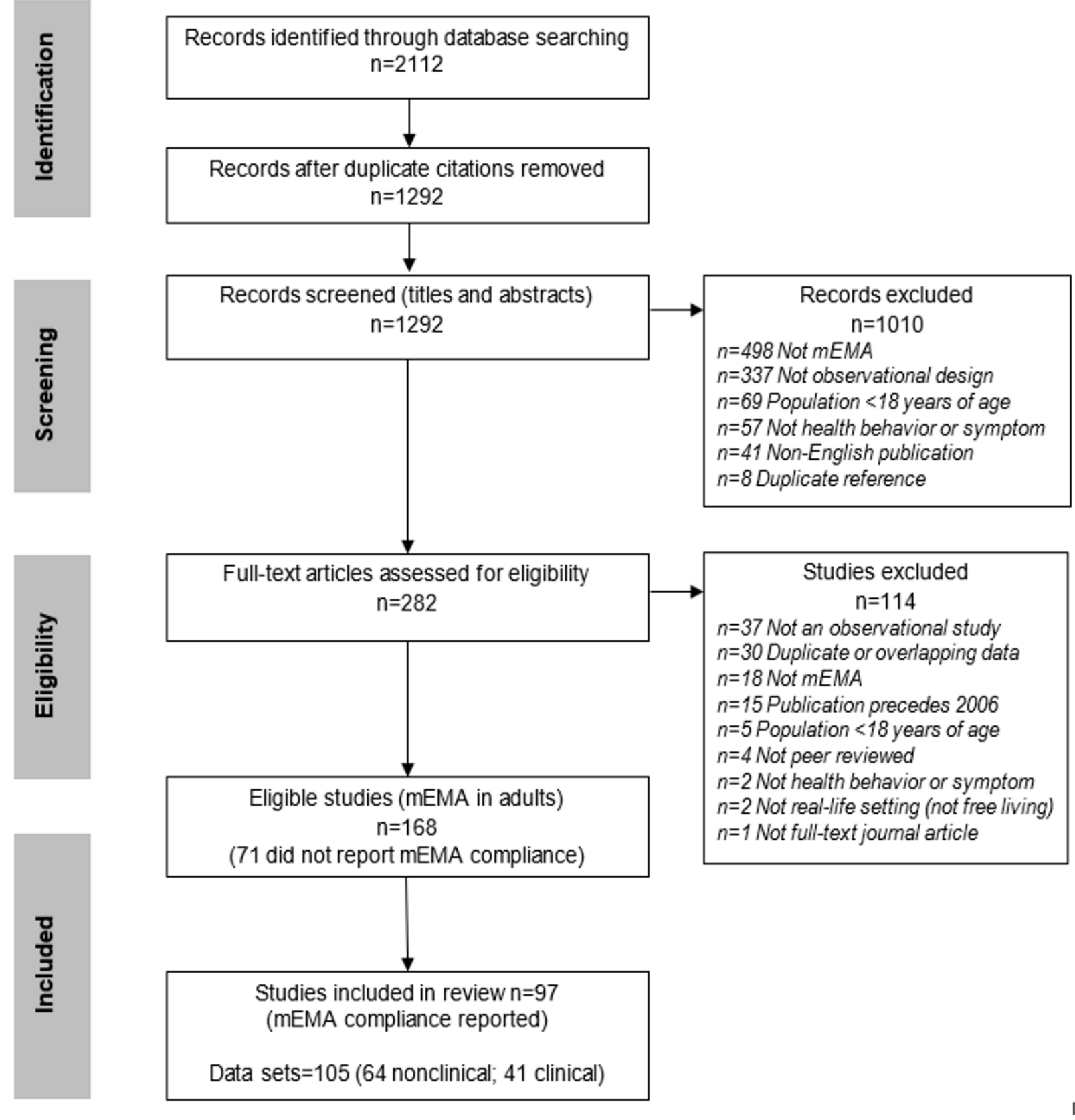

\section{Objective 1: Health-Related Behaviors and Psychological Constructs Assessed With mEMA}

Using the primary mEMA target, data sets were grouped into 2 broad domains: Behavior or Psychological construct. Within the Behavior domain, the Other category reflects single studies (7), where the primary mEMA target did not align with more common behavior targets (social interactions/activities [26,27], sexual [28], leisure [29], nonsuicidal self-injurious [30], HIV prevention [31], and oral behaviors) [32].

The most frequent primary mEMA target across all domains for nonclinical and clinical data sets was affect $(31 / 105,29.5 \%$ of data sets; nonclinical $n=15 / 64,14 \%$, clinical $n=16 / 41,15 \%$ ). The most common primary mEMA target in nonclinical data sets $(n=64)$ reflected the Behavior domain (total 38/64, 59\%), whereas clinical data sets $(n=41)$ reflected the Psychological domain (total 32/41, 78\%).

With the exception of 1 clinical study (fatigue) [33], the remaining data sets included mEMA items/questions beyond the primary mEMA target. The most frequent secondary targets assessed were affect $(50 / 105,47.6 \%)$, social environment $(33 / 105,31.4 \%)$, physical activity $(25 / 105,23.8 \%)$, cognition $(24 / 105,22.8 \%)$, and physical environment $(20 / 105,19 \%)$. Multimedia Appendix 2 presents a summary of secondary mEMA targets and participant characteristics grouped by the primary mEMA target.

\section{Objective 2: mEMA Protocol and Compliance Reporting}

Multimedia Appendix 3 presents a summary of mEMA protocols grouped by primary mEMA target. Among the included studies, 
mEMA data were most commonly collected using handheld computer/PDAs $(61 / 105,58.1 \%)$ with mobile phones accounting for approximately one-third (37/105, 35.2\%). Participant training in mEMA was reported by most studies (nonclinical: 49/64, $77 \%$; clinical: $35 / 41,85 \%$ ). The provision of incentive (financial or other) was more frequent in nonclinical protocols (nonclinical: 46/64, 72\%; clinical: 20/41, 49\%).

Across all data sets $(n=105)$, the median monitoring duration for mEMA protocols was 7 days (range: 1-182 days), with durations differing between nonclinical (median 7 days, range 1-49 days) and clinical protocols (median 12 days, range 1-182 days). Most studies included a single prompt type (overall data sets: 69/105, 65.7\%; nonclinical: 40/64, 63\%; clinical: 29/41, $71 \%$ ), with random signals being the most common in nonclinical protocols $(49 / 64,77 \%)$ and interval in clinical protocols $(25 / 41,61 \%)$. Of the remaining study protocols, $23 \%$ (24/105) of studies included 2 prompt types and $11 \%(12 / 105)$ protocols included all 3 prompt types (random signal, interval, and event-based). The frequency of time-based prompts (signal or interval) ranged from 1 to 42 per day (median: nonclinical=5, range 1-36; clinical=4, range $=1-42$ ). The number of specific questions/items within a standard prompt varied markedly across study protocols; it ranged between 1 and 73 (median: nonclinical $=10$; clinical $=8$ ).

Table 1 presents a summary of reporting for compliance metrics for mEMA time-based prompts (ie, signal and fixed prompts). Participant attrition (dropout) rates were reported or could be calculated for half of the 105 data sets (nonclinical: 31/64, 48\%; clinical: 22/41, 54\%). Less than half of the data sets reported the number of prompts delivered (overall: 22/105, 21\%; nonclinical: $14 / 64,22 \%$; clinical: $8 / 41,20 \%$ ) or answered (overall: 43/105, 41\%; nonclinical: 29/64, 45\%; clinical: 14/41,
$34 \%$ ). Approximately one-third of the data sets reported a criterion for valid mEMA data or reasons for data exclusions (overall: 37/105, 35\%; nonclinical: 25/64, 39\%; clinical: 12/41, $29 \%$ ). Criteria for valid EMA data fell into 2 main groups, with the most common based on assessment completion (ie, specified threshold for number of prompts completed per day or percentage of overall compliance), followed by response latency period threshold (eg, prompt required to be answered within 30 min). Of the data sets reporting a criterion for response time (overall: 38/105, 36\%; nonclinical: 16/64, 25\%; clinical: 22/41, $54 \%$ ), this ranged from 1.5 to $60 \mathrm{~min}$ (median $15 \mathrm{~min}$; Multimedia Appendix 3). Other reasons for data exclusion were based on specific time of day prompts (excluding the first or last of the day), technical malfunctions, or unspecified (eg, general statements on participants' limited or poor compliance).

Of the 105 data sets, $82 / 105(78.1 \%)$ reported compliance using a single metric (cohort, average per person or other), with compliance at the cohort level most common (overall: 62/105, 59\%; nonclinical: 34/64, 53\%; clinical: 28/41, 68\%). Compliance was less frequently reported using the single metric of average per person (overall: 20/105, 19\%; nonclinical: 14/64, $22 \%$; clinical: $6 / 41,15 \%$ ) or compliance for both cohort and average per person (overall: 18/105, 17\%; nonclinical: 12/64, 19\%; clinical: $6 / 41,15 \%)$. The remaining data sets $(n=5$; nonclinical: $n=4$, clinical: $n=1$ ) reported compliance after combining event/time-based signals [34] or separate tasks [35], number of completed protocol days [36], total number of prompts (data) available [37], or proportion of completed questions/items per prompt [38]. Cohort compliance reported before data exclusions ranged from $38 \%$ to $98 \%$ (median $82 \%$ ) and after data exclusions from $50 \%$ to $97 \%$ (median $81 \%$; Table 1). 
Table 1. Summary of mobile ecological momentary assessment (mEMA) compliance reporting.

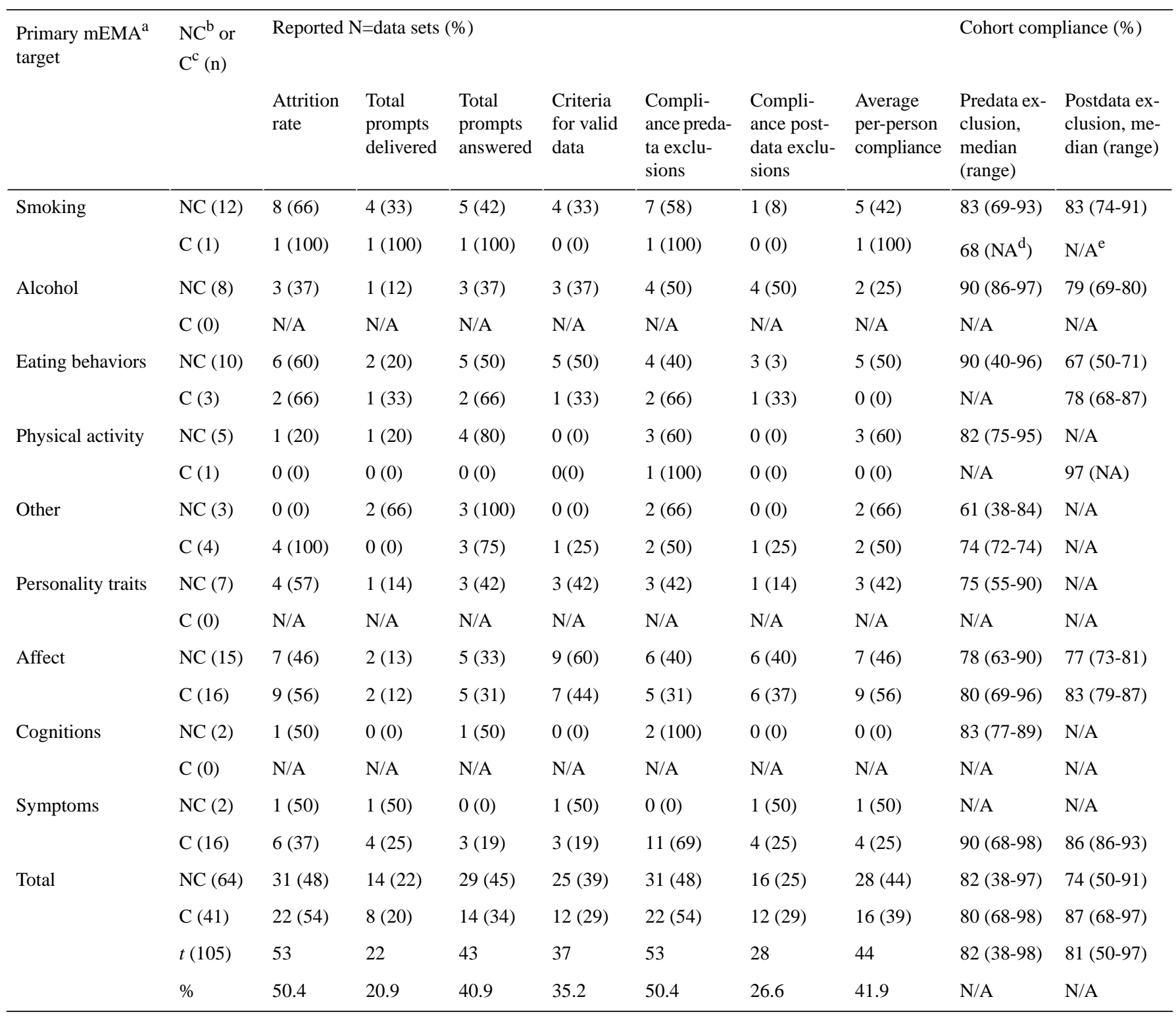

a mEMA: mobile ecological momentary assessment.

${ }^{\mathrm{b}} \mathrm{NC}$ : nonclinical.

${ }^{\mathrm{c}} \mathrm{C}$ : clinical.

${ }^{\mathrm{d}} \mathrm{NA}$ : not available as domain includes a single study.

${ }^{\mathrm{e}} \mathrm{N} / \mathrm{A}$ : not applicable.

\section{Question 3: Associations Between Key Features of mEMA Protocols and mEMA Compliance}

Of the 105 data sets included in this review, 65\% reported sufficient data for inclusion in the meta-analysis $(n=68$ data sets: 41/105 [39\%] ES nonclinical and 27/105 [26\%] ES clinical); Multimedia Appendix 1) [20,21,23,26,27, 29-31,33,36,39-90]. The remaining data sets did not report cohort compliance but reported average per-person compliance $[19,24,25,91-106,28,32]$ or other [34,35,37,38,107-110], or where cohort compliance was reported, a variable required for the meta-analysis was not [111-114].

The overall compliance rate across all 68 ESs was $81.9 \%$ (95\% CI 79.1-84.4). There was sizable heterogeneity across the compliance rates $\left(\mathrm{I}^{2}=98\right)$. Sensitivity analysis exploring the impact of pre and postdata exclusion compliance rates showed no significant difference $(P=.67$; before exclusion: $\mathrm{n}=50,81.6 \%$; after exclusion: $\mathrm{n}=18,82.8 \%)$. There was no significant difference $(P=.16)$ between the pooled compliance of nonclinical studies $\left(80.4 \% ; 95 \%\right.$ CI 76.1-83.9; $\left.\mathrm{I}^{2}=98.6\right)$ and clinical studies (84.2\%; 95\% CI 80.1-87.4; $\left.\mathrm{I}^{2}=95.7\right)$. Three studies included more than 1 data set and reported compliance ESs for each (data sets $n=2$ [23], $n=3$ [20], and $n=4$ [21]). Sensitivity analysis was undertaken to explore the impact of double counting of mEMA protocol factors within the meta-analysis, where multiple ESs were reported within single studies. When a single ES was retained for each of these studies (lowest ES of the 2 [23], median of 3 [20], ES closest to the average for 4 [21]), the 
pooled 62 ESs $(81.3 \%, 95 \%$ CI 78.2-84.2) and reported variance $\left(\mathrm{I}^{2}=98\right)$ were essentially the same as the full data set (68 ESs: $81.9 \%$; $95 \%$ CI 79.1-84.4; $\mathrm{I}^{2}=98$ ). To ensure that subgroup analysis was not affected, all analyses were conducted without duplicate ESs, and all relationships were consistent with those of the full data set.

For nonclinical studies, 2 factors (prompt frequency and items/prompt) were significantly related to mEMA compliance. For prompt frequency, the overall model was nonsignificant $(P=.07)$, but the coefficient was significant $(P<.001)$. Prompting 1 to 3 times per day was associated with higher compliance (87\%; 95\% CI 82.5-90.4) compared with studies with more than 3 prompts per day $(76.9 \%)$ and 6 or more prompts per day (79.4\%). The number of items per prompt was significant for both the overall model $(P=.04)$ and the coefficient $(P<.001)$.
Factor analysis showed that prompts with more than 26 items had significantly lower compliance $(63 \%$; $95 \%$ CI $42.3-79.7)$ compared with prompts with $\leq 26$ items (categories: $\leq 5$; $>5$ to $\leq 9$; $>9.5$ to $\leq 26$; compliance range: $84 \%-78.6 \%$ ).

For clinical data sets $(\mathrm{n}=27)$, no factors were significantly related to compliance. The number of items per prompt approached significance $(P=.05)$. Compliance appeared to be lower in studies with $9.5-26$ items per prompt $(71.1 \%$; 95\% CI 62.5-78.6). Significant heterogeneity was reported for all significant findings (nonclinical and clinical), with $\mathrm{I}^{2}$ values in excess of $90 \%$, suggesting that although some variance can be explained by the significant factors, a large amount of variance remained unexplained. The burden score was not significantly related to compliance. The meta-analysis factor analysis compliance proportions are presented in Table 2. 
Table 2. Meta-analysis results for clinical and nonclinical data sets.

\begin{tabular}{|c|c|c|c|c|}
\hline \multirow{2}{*}{$\begin{array}{l}\text { Characteristics } \\
\text { Protocol factors }\end{array}$} & \multicolumn{2}{|c|}{ Clinical data sets, $n=27$} & \multicolumn{2}{|c|}{ Nonclinical data sets, $n=41$} \\
\hline & $\mathrm{n}(\%)$ & Pooled compliance $(95 \% \mathrm{CI})$ & $\mathrm{n}(\%)$ & Pooled compliance $(95 \% \mathrm{CI})$ \\
\hline \multicolumn{5}{|c|}{ Monitoring period, day } \\
\hline$<7$ & $12(44)$ & $81.6(74.1-87.3)$ & $24(58)$ & $77.4(71.3-85.5)$ \\
\hline$>7$ to $\leq 14$ & $4(15)$ & $84.4(74.3-91.1)$ & $9(22)$ & $82.1(71.30-89.5)$ \\
\hline$>14$ & $11(41)$ & $86.7(81.2-91.0)$ & $8(19)$ & $85.3(80.5-89.1)$ \\
\hline \multicolumn{5}{|l|}{ Device $^{a}$} \\
\hline Mobile & $5(19)$ & $88.6(71.5-96.1)$ & $17(41)$ & $78.6(71.9-84.0)$ \\
\hline PDA & $18(66)$ & $81.9(77.4-85.8)$ & $22(54)$ & $80.2(74.2-84.9)$ \\
\hline Other & $4(15)$ & $88.8(82.4-93.1)$ & $2(5)$ & $92.2(86.3-95.7)$ \\
\hline \multicolumn{5}{|l|}{ Training } \\
\hline Yes & $23(85)$ & $84.4(79.7-88.4)$ & $36(88)$ & $80.4(76.0-84.3)$ \\
\hline No & $0(0)$ & $\mathrm{N} / \mathrm{A}^{\mathrm{b}}$ & $0(0)$ & N/A \\
\hline $\mathrm{NR}^{\mathrm{c}}$ & $4(15)$ & $82.8(78.4-86.4)$ & $6(15)$ & $77.7(73.1-82.0)$ \\
\hline \multicolumn{5}{|l|}{ Incentives } \\
\hline Yes & $13(48)$ & $83.6(77.7-88.3)$ & $35(85)$ & $80.4(79.0-84.3)$ \\
\hline No & $0(0)$ & N/A & $6(15)$ & $77.9(73.1-82.0)$ \\
\hline NR & $18(66)$ & $85.7(81.3-89.3)$ & $0(0)$ & N/A \\
\hline \multicolumn{5}{|c|}{ Prompt frequency, per day } \\
\hline $1-3$ & $8(30)$ & $85.3(77.6-90.7)$ & $8(19)$ & $87.0(82.5-90.4)$ \\
\hline $4-5$ & $12(44)$ & $81.5(75.8-85.9)$ & $16(39)$ & $76.9(70.1-82.5)$ \\
\hline$\geq 6$ & $6(22)$ & $86.3(74.1-92.4)$ & $17(41)$ & $79.4(71.1-85.5)$ \\
\hline $\mathrm{UTD}^{\mathrm{d}}$ & $1(4)$ & 90.6 (N/A) & $0(0)$ & N/A \\
\hline \multicolumn{5}{|l|}{ Burden score } \\
\hline $0-283.5$ & $4(15)$ & $86.2(76.9-92.4)$ & $11(27)$ & $80.5(75.7-84.6)$ \\
\hline $284-810$ & $7(26)$ & $86.4(75.4-93.0)$ & $10(24)$ & $79.6(73.7-84.7)$ \\
\hline $811-1806$ & $3(11)$ & $88.8(64.8-97.1)$ & $13(31)$ & $82.8(73.7-89.1)$ \\
\hline$\geq 1807$ & $7(26)$ & $85.3(80.5-89.0)$ & $4(10)$ & $79.1(51.5-93.1)$ \\
\hline \multicolumn{5}{|c|}{ Items per prompt } \\
\hline$<5$ & $8(30)$ & $87.2(80.7-91.9)$ & $10(24)$ & $82.8(77.2-87.2)$ \\
\hline 5 to $\leq 9.5$ & $7(26)$ & $88.4(76.9-94.6)$ & $8(19)$ & $78.6(67.5-86.8)$ \\
\hline 9.5 to $\leq 26$ & $2(7)$ & $71.1(62.5-78.6)$ & $16(39)$ & $84.0(79.0-88.0)$ \\
\hline$>26$ & $6(22)$ & $87.2(82.9-90.7)$ & $4(10)$ & $63.0(42.3-79.7)$ \\
\hline NR & $5(19)$ & $72.7(68.4-76.9)$ & $3(7)$ & $70.3(40.4-89.2)$ \\
\hline \multicolumn{5}{|c|}{ Number of prompt types } \\
\hline 1 & $18(66)$ & $82.6(78.1-86.5)$ & $25(61)$ & $79.6(75.0-83.5)$ \\
\hline 2 & $6(22)$ & $86.4(71.3-94.2)$ & $11(27)$ & $83.3(71.7-90.9)$ \\
\hline 3 & $3(11)$ & $87.2(85.5-88.8)$ & $5(12)$ & $77.7(65.7-86.5)$ \\
\hline
\end{tabular}

${ }^{a}$ Device type included with categories: Mobile phone (total $\mathrm{n}=22$; smartphone: clinical $\mathrm{n}=1$; nonclinical $\mathrm{n}=14$; mobile: clinical $\mathrm{n}=4$, nonclinical $\mathrm{n}=3$ ); PDA (total $n=45$; clinical $n=22$, nonclinical $n=23$ ); Other (total $n=6$; electronic diary: clinical $n=2$, nonclinical $n=1$; iPod: clinical $n=1$, nonclinical $n=1$; watch device: clinical $n=1$ ).

${ }^{\mathrm{b}} \mathrm{N} / \mathrm{A}$ : not applicable.

${ }^{\mathrm{c}} \mathrm{NR}$ : not reported. 
${ }^{\mathrm{d}}$ UTD: unable to be determined.

\section{Discussion}

\section{Principal Findings}

This systematic review of observational studies aimed to describe protocols and compliance with mEMA for self-reported health-related behaviors and psychological constructs in adults. Across 105 unique data sets, the key findings of this review were as follows: (1) a variety of health-related behaviors and psychological constructs were assessed, with affect being the most common mEMA target; (2) mEMA protocols varied widely across studies; (3) compliance was inconsistently reported across studies; (4) meta-analysis estimated an overall compliance rate of $81.9 \%$ (95\% CI 79.1-84.4), with no significant difference between nonclinical and clinical data sets or estimates before or after data exclusions; (5) compliance was associated with prompts per day and items per prompt (nonclinical); and 6) no compelling relationship was identified between key features of mEMA protocols representing burden and mEMA compliance.

\section{mEMA Use in Adults for Health-Related Behaviors and Psychological Constructs}

The mEMA targets identified in this review reflect those reported in previous systematic reviews: affect/mood $[7,12,14,15]$, cognitions [13], symptoms [15], eating or dietary behaviors [10,11], physical activity [10], and smoking or alcohol consumption $[5,6]$. Likewise, clinical populations identified in this review (psychiatric or mental health conditions, chronic pain and fibromyalgia, eating disorders, and substance use) were generally consistent with those reported previously [5,7,11,12,14-16]. However, there were chronic conditions unique to this review: oral or dental health, cancer, stroke and traumatic brain injury (for each $n=3,9 / 41,22 \%$ ), HIV, and upper abdominal surgery (for each $n=1,2 / 41,5 \%$ ). The small number of studies identified for these clinical groups may suggest that the potential for mEMA has not yet been realized in these populations.

\section{Reporting of mEMA Protocols and Compliance}

Most studies included in this review provided information around the EMA protocol used (device, monitoring duration, frequency and type of prompts, provision of training, and use of incentives). Consistent with previous systematic reviews of both youth and adults, there was considerable heterogeneity across studies for EMA protocols (Multimedia Appendix 3). Heterogeneity may be expected given the various potential applications of this survey approach. The mEMA protocol required to obtain sufficient or appropriate self-reported data on daily habitual behaviors in the general population is not likely to be the same as that for obtaining self-reported data on psychological responses to events or stimuli in clinical contexts. For example, the average EMA monitoring duration for studies of nonclinical adults in this review was 7 days (range: 1-49 days) compared with 12 days (range: 1-182 days) for clinical populations and 30 days (range: 3-730 days) in a review of EMA in substance users [5]. Likewise, prompt type, frequency, and complexity are expected to differ depending on the EMA target and population. Reviews of studies of EMA for diet and physical activity (common behaviors) report a daily average prompt frequency of 20 [10] compared with less than 4 prompts per day in substance use [5]. For these reasons, in systematic reviews of EMA use-including this one-reporting of summary metrics (mean, SD, median, range) for protocol components could be interpreted as a reflection of diversity in EMA application rather than a lack of protocol standardization.

The same rationale cannot be applied to the inconsistencies identified in reporting of EMA protocol compliance. Compliance is problematic to determine for event-based prompts (eg, those completed with smoking or consumption of alcohol). Compliance for time-based notifications, especially when the EMA is conducted using mobile devices, is relatively simple (number of prompts answered out of the total number of prompts delivered). However, participants may respond to a notification but may not complete all survey items or may not respond in a timely manner, affecting the momentary aspect of the EMA. In both of these cases, the act of responding might appropriately contribute to compliance rates, but the data are unlikely to be valid. These concepts were evident in the earliest recommendations for reporting compliance in EMA studies [17], which predate the sampling frame of this systematic review (2006-2016 inclusive). Considering that 71 studies were excluded from this review because of the absence of reporting mEMA compliance, less than half of the studies included in this review complied with recommendations put forward by Stone and Shiffman [17], such as reporting the proportion of delivered prompts answered $(43 / 105,41 \%)$ or defining a criterion for valid EMA data $(37 / 105,35 \%)$. Similarly, less than half of the data sets included in this review reported an average number of prompts answered per person (44/105, 42\%), as recommended by more recently published guidelines for reporting EMA $[8,10]$.

With the growth of systematic review methodologies (meta-synthesis, meta-regression, etc), one aspect of reporting for EMA warrants further consideration. EMA allows collection of self-report data across multiple survey items reflecting a range of behavioral, psychological, and contextual factors. It is not uncommon for data collected in the original, primary study to be reported in several publications. The foci of these offspring publications may include the total original sample of participants recruited (eg, unpublished data for specific mEMA items or other variables) or explore a subset of the original study participants (eg, patterns associated with participant characteristics). Although this is a reasonable and defensible use of the original study's resources, identification of duplicate or overlapping data in studies can be problematic. Where ambiguity exists, contacting the study authors is one way to clarify which publication should be considered the primary report (and which report overlapping or duplicate data). However, this option becomes less practical as time and people move on. The alternative is for authors to include an explicit statement concerning the existence of publications that include overlapping or duplicate data. There were a number of exemplars of this aspect of reporting in studies included $[67,68,96]$ and excluded from this review [115-118]. 


\section{Associations Between Key Components of mEMA Protocols and Compliance: Meta-analysis}

In our meta-analysis (68 data sets), which replicates and was guided by the authors of 2 previous meta-analyses on this topic $[5,9]$, the overall compliance rate was $81.9 \%$ (95\% CI 79.1-84.4). This was slightly higher than that reported by Wen et al [9] $(78.26 \% ; 95 \%$ CI 75.49-80.78) and Jones et al [5] (75.06\%; 95\% CI 72.37-77.65). Although concerns have been expressed about the relationship between EMA burden and compliance, it remains unclear whether, or which, EMA protocol factors affect participant compliance. In our meta-analysis, for nonclinical data sets, prompt frequency per day and the number of items per prompt were significantly related to compliance (noting that it is not unusual for coefficients derived within a model to be significant even when the overall model is not). However, the findings are likely affected by the number of data sets in some categories. For nonclinical data sets, frequencies of 1-3 prompts per day were associated with small but significantly higher mean cohort compliance. Higher compliance with lower number of prompts perhaps seems intuitive, yet the evidence is inconsistent. Wen et al [9] reported opposite patterns of significance when nonclinical and clinical population data were investigated, and Jones et al [5] and Ono et al [119] reported no relationship with prompt frequency and compliance among substance users and those affected by chronic pain, respectively.

The relationship between the number of items included within each prompt and compliance has not been explored in previous systematic reviews or meta-analyses of mEMA. In this review, the number of items respondents were required to complete in a standard prompt ranged from 1 to 73 (median 10), with a greater number of items more common in the mEMA of psychological constructs (Multimedia Appendix 3). Our analysis showed an intuitive relationship with compliance among nonclinical data (ie, $\geq 26$ items per prompt had the lowest mean cohort compliance of $63 \%$; $95 \%$ CI $42.3-79.7)$, but not with clinical data.

When aiming to identify protocol factors affecting compliance, the inconsistencies in reporting of EMA compliance and the likely publication bias (studies with lower compliance rates may not be submitted or accepted for publication) must also be considered [5]. These factors limit the inclusion of potentially eligible studies in meta-analyses $(68 / 105,64.8 \%$ data sets in this review; 36/42, 86\% studies in a previous review [9]). In addition, studies included in meta-analyses privilege best compliers through exclusion of participants not meeting criteria for valid EMA data or compliance thresholds (determined a priori or posteriori). Jones et al [5] attempted to address this latter point by exploring protocol factors associated with participant data exclusions (monitoring duration and prompt frequency). Finally, aggregate level compliance may not be sensitive enough or provide sufficient resolution to identify factors associated with higher or lower compliance. While accepting these caveats, there are 2 ways to consider the results of the 3 meta-analyses undertaken by Wen et al [9], Jones et al [5], and this study:
1. There is insufficient resolution to identify associations-if they exist - at the aggregate data level.

2. Although confidence limits might be reduced by adding further studies, the meta-analyses are essentially correct, and the notion of protocol burden imposed on participants has little to no impact on compliance [4,5].

In studies using EMA, the issue of what constitutes an acceptable rate of compliance or missing data is debatable. Although several studies included in this review cite a criterion or commonly used threshold of $80 \%$, we, similar to Jones et al [5], could not identify the derivation of this criterion. For authors currently planning, conducting, or writing papers or protocols on EMA to monitor health-related behaviors of psychological constructs, adequate recording and reporting of compliance data following recommendations by Liao et al [10] and Heron et al [8] should enable future meta-analyses to explore protocol factors affecting participant compliance rates.

This systematic review prospectively aimed to sample a decade of mEMA use (protocol registered in November 2016; sampling frame of 2006 to 2016) in observational studies including adults from clinical and nonclinical populations. As one of the first EMA reporting documents was published in 2002 [17], this sampling frame assumed that researchers planning or reporting studies including mEMA would be aware of these reporting recommendations. The time frame required for the uptake of EMA reporting recommendations is unknown, although estimates of the time required for uptake of translational research ranges between 2 and 17 years [120]. Our sampling frame and review, however, does not capture studies published from 2017 to date. It is possible that more recent publications differ from those included in our review (greater mobile phone use, better reporting of mEMA schedules, and compliance).

There are no universally accepted recommendations concerning the updating of systematic searches or incorporation of the newer studies into the review results. Systematic reviews-depending on the specific question and volume of studies eligible for inclusion-are time- and labor-intensive. For larger reviews, it is not uncommon for these to take $>2$ years [121], with updates of Cochrane Collaboration systematic reviews taking up to 3.3 years [122]. The current Cochrane Collaboration policy infers that the decision to update a systematic review should consider the importance of the review question and the volume of new information (studies) [122]. Early in the review process (postsearch completion), 2 papers were identified, published in 2016 [10] and 2017 [8], providing updated recommendations for EMA reporting. Although the volume of mEMA studies published from 2017 is substantial and growing, we opted not to undertake an updated search/meta-analysis to quarantine mEMA studies published before the availability of the more recent EMA reporting recommendations.

\section{Strengths and Limitations}

This review was strengthened by the broad eligibility criteria used, including studies across nonclinical and clinical contexts in adults. The meta-analysis method was replicated from previous studies [5,9], enabling direct comparison of findings. To the best of the authors' knowledge, this review is the first to propose and explore burden as a compound effect of the 
various EMA factors (monitoring duration, prompt frequency and prompt type, item per prompt) on participant compliance. We have proposed this novel metric as a starting point for conversations, critique, and further development. In its current form, the burden metric does not include all factors likely to contribute to burden (unfamiliarity with technology, adjunctive use of wearable technologies such as accelerometers), the proposed weighting is rudimentary, and the accuracy of study design features was not confirmed by the study authors.

Limitations of this review include a search strategy focused on the use of mEMA and excluding interventions delivered using EMA (EMI). Consequently, the findings of this review should not be extrapolated or assumed to be similar in studies using EMI. Most studies included in this review provided a clear statement of the primary outcome of interest within each observational study, and we are confident that our categorization of primary mEMA targets is defensible. However, when observational studies did not clearly identify or infer a primary outcome of interest and given mEMA survey items can include multiple items for both self-reported behavioral and psychological constructs, for a small number of studies, misclassification may exist with respect to categorization of mEMA targets as primary or secondary. In the absence of explicit statements by the authors on the number of items within each standard notification, we adopted a conservative approach by estimating the minimum compulsory number of items based on either the information provided by authors within publications or reviewing the instruments reported by authors for inclusion within surveys. The impact of including only studies published in English is unknown.

\section{Conclusions}

This review suggests that there is substantial interest in the use of mEMA in adults to collect self-reported health-related behavior and psychological construct data in nonclinical and clinical contexts. Across mEMA studies, there was considerable heterogeneity in protocol design, which may reflect a concerted effort by researchers to tailor mEMA protocols for the intended target and/or population to facilitate compliance. However, the number of studies reporting participant compliance with EMA is concerning. As a result of no or underreporting of compliance, pooled compliance rates may be skewed in favor of overall higher EMA compliance rates. This may dampen associations between compliance rates and EMA protocol factors or burden, making it difficult to ascertain which, if any, protocol factors (such as prompt frequency and number of items within prompts, as identified in this analysis) improve compliance and data collection.

\section{Acknowledgments}

The authors sincerely thank Dr Cheng Wen and Dr Andrew Jones for their guidance regarding the meta-analysis process. This study was supported by the University of South Australian High Achiever Vacation scholarship scheme (authors AG and JI). This study was not sponsored.

\section{Authors' Contributions}

All authors contributed to this systematic review through the initiation and development of the original protocol (MW, HL, and $\mathrm{FF}$ ), search and screening (AG and JI), data extraction (AG, JI, MW, HL, FF, and KF), synthesis and meta-analysis (KF, HL, $\mathrm{FF}$, and MW), manuscript development, and final review (MW, HL, KF, FF, AG, and JI).

\section{Conflicts of Interest}

None declared.

\section{Multimedia Appendix 1}

Ecological momentary assessment (EMA) population and compliance characteristics for studies included within review. [DOCX File, $81 \mathrm{~KB}-$ Multimedia Appendix 1]

\section{Multimedia Appendix 2}

Summary of mobile ecological momentary assessment (mEMA) targets and participant characteristics in nonclinical and clinical mEMA studies.

[DOCX File , 67 KB-Multimedia Appendix 2]

\section{Multimedia Appendix 3}

Summary of mobile ecological momentary assessment protocols. [DOCX File , 63 KB-Multimedia Appendix 3]

\section{References}

1. Burke LE, Shiffman S, Music E, Styn MA, Kriska A, Smailagic A, et al. Ecological momentary assessment in behavioral research: addressing technological and human participant challenges. J Med Internet Res 2017 Mar 15;19(3):e77 [FREE Full text] [doi: 10.2196/jmir.7138] [Medline: 28298264] 
2. Dunton GF. Ecological momentary assessment in physical activity research. Exerc Sport Sci Rev 2017 Dec;45(1):48-54 [FREE Full text] [doi: 10.1249/JES.0000000000000092] [Medline: 27741022]

3. Rintala A, Wampers M, Myin-Germeys I, Viechtbauer W. Response compliance and predictors thereof in studies using the experience sampling method. Psychol Assess 2019 Feb;31(2):226-235. [doi: 10.1037/pas0000662] [Medline: 30394762]

4. Shiffman S, Stone AA, Hufford MR. Ecological momentary assessment. Annu Rev Clin Psychol 2008;4:1-32. [doi: 10.1146/annurev.clinpsy.3.022806.091415] [Medline: 18509902]

5. Jones A, Remmerswaal D, Verveer I, Robinson E, Franken IH, Wen CK, et al. Compliance with ecological momentary assessment protocols in substance users: a meta-analysis. Addiction 2019 Apr;114(4):609-619. [doi: 10.1111/add.14503] [Medline: $\underline{30461120]}$

6. Freedman MJ, Lester KM, McNamara C, Milby JB, Schumacher JE. Cell phones for ecological momentary assessment with cocaine-addicted homeless patients in treatment. J Subst Abuse Treat 2006 Mar;30(2):105-111. [doi:

10.1016/j.jsat.2005.10.005] [Medline: 16490673]

7. Baltasar-Tello I, Miguélez-Fernández C, Peñuelas-Calvo I, Carballo JJ. Ecological momentary assessment and mood disorders in children and adolescents: a systematic review. Curr Psychiatry Rep 2018 Aug 01;20(8):66. [doi: 10.1007/s11920-018-0913-z] [Medline: 30069650]

8. Heron KE, Everhart RS, McHale SM, Smyth JM. Using mobile-technology-based ecological momentary assessment (EMA) methods with youth: a systematic review and recommendations. J Pediatr Psychol 2017 Nov 01;42(10):1087-1107. [doi: 10.1093/jpepsy/jsx078] [Medline: 28475765]

9. Wen CKF, Schneider S, Stone AA, Spruijt-Metz D. Compliance with mobile ecological momentary assessment protocols in children and adolescents: a systematic review and meta-analysis. J Med Internet Res 2017 Apr 26;19(4):e132 [FREE Full text] [doi: 10.2196/jmir.6641] [Medline: 28446418]

10. Liao Y, Skelton K, Dunton G, Bruening M. A systematic review of methods and procedures used in ecological momentary assessments of diet and physical activity research in youth: an adapted STROBE checklist for reporting EMA studies (CREMAS). J Med Internet Res 2016 Jun 21;18(6):e151 [FREE Full text] [doi: 10.2196/jmir.4954] [Medline: 27328833]

11. Schembre SM, Liao Y, O'Connor SG, Hingle MD, Shen S, Hamoy KG, et al. Mobile ecological momentary diet assessment methods for behavioral research: systematic review. JMIR Mhealth Uhealth 2018 Nov 20;6(11):e11170 [FREE Full text] [doi: 10.2196/11170] [Medline: $\underline{30459148]}$

12. Miguelez-Fernandez C, de Leon SJ, Baltasar-Tello I, Peñuelas-Calvo I, Barrigon ML, Capdevila AS, et al. Evaluating attention-deficit/hyperactivity disorder using ecological momentary assessment: a systematic review. Atten Defic Hyperact Disord 2018 Dec;10(4):247-265. [doi: 10.1007/s12402-018-0261-1] [Medline: 30132248]

13. Moore RC, Swendsen J, Depp CA. Applications for self-administered mobile cognitive assessments in clinical research: a systematic review. Int J Methods Psychiatr Res 2017 Dec;26(4):e1562 [FREE Full text] [doi: 10.1002/mpr.1562] [Medline: 28370881]

14. Bos FM, Schoevers RA, aan het Rot M. Experience sampling and ecological momentary assessment studies in psychopharmacology: a systematic review. Eur Neuropsychopharmacol 2015 Nov;25(11):1853-1864. [doi: 10.1016/j.euroneuro.2015.08.008] [Medline: 26336868]

15. May M, Junghaenel DU, Ono M, Stone AA, Schneider S. Ecological momentary assessment methodology in chronic pain research: a systematic review. J Pain 2018 Jul;19(7):699-716. [doi: 10.1016/j.jpain.2018.01.006] [Medline: 29371113]

16. Bell IH, Lim MH, Rossell SL, Thomas N. Ecological momentary assessment and intervention in the treatment of psychotic disorders: a systematic review. Psychiatr Serv 2017 Nov 01;68(11):1172-1181. [doi: 10.1176/appi.ps.201600523] [Medline: 28669284]

17. Stone AA, Shiffman S. Capturing momentary, self-report data: a proposal for reporting guidelines. Ann Behav Med 2002;24(3):236-243. [Medline: 12173681]

18. Sampson M, McGowan J, Cogo E, Grimshaw J, Moher D, Lefebvre C. An evidence-based practice guideline for the peer review of electronic search strategies. J Clin Epidemiol 2009 Sep;62(9):944-952. [doi: 10.1016/j.jclinepi.2008.10.012] [Medline: 19230612]

19. Solhan MB, Trull TJ, Jahng S, Wood PK. Clinical assessment of affective instability: comparing EMA indices, questionnaire reports, and retrospective recall. Psychol Assess 2009 Sep;21(3):425-436 [FREE Full text] [doi: 10.1037/a0016869] [Medline: 19719353$]$

20. Sorbi MJ, Peters ML, Kruise DA, Maas CJ, Kerssens JJ, Verhaak PF, et al. Electronic momentary assessment in chronic pain I: psychological pain responses as predictors of pain intensity. Clin J Pain 2006 Jan;22(1):55-66. [doi: 10.1097/01.ajp.0000148624.46756.fa] [Medline: 16340594]

21. Johnson EI, Grondin O, Barrault M, Faytout M, Helbig S, Husky M, et al. Computerized ambulatory monitoring in psychiatry: a multi-site collaborative study of acceptability, compliance, and reactivity. Int J Methods Psychiatr Res 2009;18(1):48-57. [doi: 10.1002/mpr.276] [Medline: 19195050]

22. Kimhy D, Vakhrusheva J, Khan S, Chang RW, Hansen MC, Ballon JS, et al. Emotional granularity and social functioning in individuals with schizophrenia: an experience sampling study. J Psychiatr Res 2014 Jun;53:141-148 [FREE Full text] [doi: 10.1016/j.jpsychires.2014.01.020] [Medline: 24561000] 
23. Ritz T, Rosenfield D, Steptoe A. Physical activity, lung function, and shortness of breath in the daily life of individuals with asthma. Chest 2010 Oct;138(4):913-918. [doi: 10.1378/chest.08-3073] [Medline: 20472861]

24. MacKerron G, Mourato S. Happiness is greater in natural environments. Glob Environ Change 2013 Oct;23(5):992-1000. [doi: 10.1016/j.gloenvcha.2013.03.010]

25. Trampe D, Quoidbach J, Taquet M. Emotions in everyday life. PLoS One 2015;10(12):e0145450 [FREE Full text] [doi: 10.1371/journal.pone.0145450] [Medline: 26698124]

26. Jean FA, Swendsen JD, Sibon I, Fehér K, Husky M. Daily life behaviors and depression risk following stroke: a preliminary study using ecological momentary assessment. J Geriatr Psychiatry Neurol 2013 Sep;26(3):138-143. [doi: 10.1177/0891988713484193] [Medline: 23584854]

27. Granholm E, Ben-Zeev D, Fulford D, Swendsen J. Ecological momentary assessment of social functioning in schizophrenia: impact of performance appraisals and affect on social interactions. Schizophr Res 2013 Apr;145(1-3):120-124 [FREE Full text] [doi: 10.1016/j.schres.2013.01.005] [Medline: 23402693]

28. Wray TB, Kahler CW, Monti PM. Using Ecological Momentary Assessment (EMA) to study sex events among very high-risk men who have sex with men (MSM). AIDS Behav 2016 Jan 8:2231-2242. [doi: 10.1007/s10461-015-1272-y] [Medline: 26746212]

29. Zawadzki MJ, Smyth JM, Costigan HJ. Real-time associations between engaging in leisure and daily health and well-being. Ann Behav Med 2015 Aug;49(4):605-615. [doi: 10.1007/s12160-015-9694-3] [Medline: 25724635]

30. Armey MF, Crowther JH, Miller IW. Changes in ecological momentary assessment reported affect associated with episodes of nonsuicidal self-injury. Behav Ther 2011 Dec;42(4):579-588. [doi: 10.1016/j.beth.2011.01.002] [Medline: 22035987]

31. Cook PF, McElwain CJ, Bradley-Springer LA. Feasibility of a daily electronic survey to study prevention behavior with HIV-infected individuals. Res Nurs Health 2010 Jun;33(3):221-234. [doi: 10.1002/nur.20381] [Medline: 20499392]

32. Kaplan SE, Ohrbach R. Self-report of waking-state oral parafunctional behaviors in the natural environment. J Oral Facial Pain Headache 2016;30(2):107-119 [FREE Full text] [doi: 10.11607/ofph.1592] [Medline: 27128474]

33. Hacker ED, Ferrans CE. Ecological momentary assessment of fatigue in patients receiving intensive cancer therapy. $\mathrm{J}$ Pain Symptom Manage 2007 Mar;33(3):267-275. [doi: 10.1016/j.jpainsymman.2006.08.007] [Medline: 17349496]

34. Chandra S, Scharf D, Shiffman S. Within-day temporal patterns of smoking, withdrawal symptoms, and craving. Drug Alcohol Depend 2011 Sep 01;117(2-3):118-125 [FREE Full text] [doi: 10.1016/j.drugalcdep.2010.12.027] [Medline: 21324611]

35. Yoshiuchi K, Cook DB, Ohashi K, Kumano H, Kuboki T, Yamamoto Y, et al. A real-time assessment of the effect of exercise in chronic fatigue syndrome. Physiol Behav 2007 Dec 05;92(5):963-968 [FREE Full text] [doi: 10.1016/j.physbeh.2007.07.001] [Medline: 17655887]

36. Thomas JG, Doshi S, Crosby RD, Lowe MR. Ecological momentary assessment of obesogenic eating behavior: combining person-specific and environmental predictors. Obesity (Silver Spring) 2011 Aug;19(8):1574-1579 [FREE Full text] [doi: 10.1038/oby.2010.335] [Medline: 21273995]

37. Ottaviani C, Medea B, Lonigro A, Tarvainen M, Couyoumdjian A. Cognitive rigidity is mirrored by autonomic inflexibility in daily life perseverative cognition. Biol Psychol 2015 Apr;107:24-30. [doi: 10.1016/j.biopsycho.2015.02.011] [Medline: 25749107]

38. Kuntsche E, Labhart F. ICAT: development of an internet-based data collection method for ecological momentary assessment using personal cell phones. Eur J Psychol Assess 2013;29(2):140-148 [FREE Full text] [doi: 10.1027/1015-5759/a000137] [Medline: 24285917]

39. Ambwani S, Roche MJ, Minnick AM, Pincus AL. Negative affect, interpersonal perception, and binge eating behavior: an experience sampling study. Int J Eat Disord 2015 Sep;48(6):715-726. [doi: 10.1002/eat.22410] [Medline: 25946681]

40. Andersson C, Söderpalm Gordh AH, Berglund M. Use of real-time interactive voice response in a study of stress and alcohol consumption. Alcohol Clin Exp Res 2007 Nov;31(11):1908-1912. [doi: 10.1111/j.1530-0277.2007.00520.x] [Medline: 17949395]

41. Berg KC, Peterson CB, Crosby RD, Cao L, Crow SJ, Engel SG, et al. Relationship between daily affect and overeating-only, loss of control eating-only, and binge eating episodes in obese adults. Psychiatry Res 2014 Jan 30;215(1):185-191 [FREE Full text] [doi: 10.1016/j.psychres.2013.08.023] [Medline: 24200217]

42. Buckner JD, Crosby RD, Wonderlich SA, Schmidt NB. Social anxiety and cannabis use: an analysis from ecological momentary assessment. J Anxiety Disord 2012 Mar;26(2):297-304 [FREE Full text] [doi: 10.1016/j.janxdis.2011.12.006] [Medline: 22246109]

43. Burt SA, Donnellan MB. Evidence that the subtypes of antisocial behavior questionnaire (STAB) predicts momentary reports of acting-out behaviors. Pers Individ Dif 2010 Jun;48(8):917-920. [doi: 10.1016/j.paid.2010.02.021]

44. Businelle MS, Ma P, Kendzor DE, Reitzel LR, Chen M, Lam CY, et al. Predicting quit attempts among homeless smokers seeking cessation treatment: an ecological momentary assessment study. Nicotine Tob Res 2014 Oct;16(10):1371-1378 [FREE Full text] [doi: 10.1093/ntr/ntu088] [Medline: 24893602]

45. Clasen PC, Fisher AJ, Beevers CG. Mood-reactive self-esteem and depression vulnerability: person-specific symptom dynamics via smart phone assessment. PLoS One 2015;10(7):e0129774 [FREE Full text] [doi: 10.1371/journal.pone.0129774] [Medline: 26131724] 
46. Courvoisier DS, Eid M, Lischetzke T, Schreiber WH. Psychometric properties of a computerized mobile phone method for assessing mood in daily life. Emotion 2010 Feb;10(1):115-124. [doi: 10.1037/a0017813] [Medline: 20141308]

47. Doherty ST, Lemieux CJ, Canally C. Tracking human activity and well-being in natural environments using wearable sensors and experience sampling. Soc Sci Med 2014 Apr;106:83-92. [doi: 10.1016/j.socscimed.2014.01.048] [Medline: 24549253]

48. Fitzsimmons-Craft EE, Bardone-Cone AM, Crosby RD, Engel SG, Wonderlich SA, Bulik CM. Mediators of the relationship between thin-ideal internalization and body dissatisfaction in the natural environment. Body Image 2016 Sep;18:113-122 [FREE Full text] [doi: 10.1016/j.bodyim.2016.06.006] [Medline: 27391791]

49. Fonareva I, Amen AM, Ellingson RM, Oken BS. Differences in stress-related ratings between research center and home environments in dementia caregivers using ecological momentary assessment. Int Psychogeriatr 2012 Jan;24(1):90-98 [FREE Full text] [doi: 10.1017/S1041610211001414] [Medline: 21777503]

50. Heron KE, Scott SB, Sliwinski MJ, Smyth JM. Eating behaviors and negative affect in college women's everyday lives. Int J Eat Disord 2014 Dec;47(8):853-859 [FREE Full text] [doi: 10.1002/eat.22292] [Medline: 24797029]

51. Heron KE, Smyth JM. Body image discrepancy and negative affect in women's everyday lives: an ecological momentary assessment evaluation of self-discrepancy theory. J Soc Clin Psychol 2013 Mar;32(3):276-295. [doi: 10.1521/jscp.2013.32.3.276]

52. Hofmann W, Wisneski DC, Brandt MJ, Skitka LJ. Morality in everyday life. Science 2014 Sep 12;345(6202):1340-1343 [FREE Full text] [doi: 10.1126/science.1251560] [Medline: 25214626]

53. Juth V, Dickerson SS, Zoccola PM, Lam S. Understanding the utility of emotional approach coping: evidence from a laboratory stressor and daily life. Anxiety Stress Coping 2015;28(1):50-70 [FREE Full text] [doi: 10.1080/10615806.2014.921912] [Medline: 24804564]

54. Kashdan TB, Collins RL. Social anxiety and the experience of positive emotion and anger in everyday life: an ecological momentary assessment approach. Anxiety Stress Coping 2010 May;23(3):259-272. [doi: 10.1080/10615800802641950] [Medline: 19326272]

55. Kirchner TR, Cantrell J, Anesetti-Rothermel A, Ganz O, Vallone DM, Abrams DB. Geospatial exposure to point-of-sale tobacco: real-time craving and smoking-cessation outcomes. Am J Prev Med 2013 Oct;45(4):379-385 [FREE Full text] [doi: 10.1016/j.amepre.2013.05.016] [Medline: 24050412]

56. Komulainen E, Meskanen K, Lipsanen J, Lahti JM, Jylhä P, Melartin T, et al. The effect of personality on daily life emotional processes. PLoS One 2014;9(10):e110907 [FREE Full text] [doi: 10.1371/journal.pone.0110907] [Medline: 25343494]

57. Lange S, Süß H. Measuring slips and lapses when they occur - ambulatory assessment in application to cognitive failures. Conscious Cogn 2014 Feb;24:1-11. [doi: 10.1016/j.concog.2013.12.008] [Medline: 24384496]

58. Liao Y, Intille SS, Dunton GF. Using ecological momentary assessment to understand where and with whom adults' physical and sedentary activity occur. Int J Behav Med 2015 Feb;22(1):51-61. [doi: 10.1007/s12529-014-9400-z] [Medline: 24639067]

59. Ramirez J, Miranda R. Alcohol craving in adolescents: bridging the laboratory and natural environment. Psychopharmacology (Berl) 2014 Apr;231(8):1841-1851 [FREE Full text] [doi: 10.1007/s00213-013-3372-6] [Medline: 24363093]

60. Riediger M, Wrzus C, Schmiedek F, Wagner GG, Lindenberger U. Is seeking bad mood cognitively demanding? Contra-hedonic orientation and working-memory capacity in everyday life. Emotion 2011 Jun;11(3):656-665. [doi: 10.1037/a0022756] [Medline: 21534659]

61. Robertson BM, Piasecki TM, Slutske WS, Wood PK, Sher KJ, Shiffman S, et al. Validity of the hangover symptoms scale: evidence from an electronic diary study. Alcohol Clin Exp Res 2012;36(1):171-177. [doi: 10.1111/j.1530-0277.2011.01592.x] [Medline: 21762183]

62. Rowan PJ, Cofta-Woerpel L, Mazas CA, Vidrine JI, Reitzel LR, Cinciripini PM, et al. Evaluating reactivity to ecological momentary assessment during smoking cessation. Exp Clin Psychopharmacol 2007 Aug;15(4):382-389. [doi: 10.1037/1064-1297.15.4.382] [Medline: 17696685$]$

63. Rutledge T, Stucky E, Dollarhide A, Shively M, Jain S, Wolfson T, et al. A real-time assessment of work stress in physicians and nurses. Health Psychol 2009 Mar;28(2):194-200. [doi: 10.1037/a0013145] [Medline: 19290711]

64. Schuster RM, Mermelstein RJ, Hedeker D. Ecological momentary assessment of working memory under conditions of simultaneous marijuana and tobacco use. Addiction 2016 Aug;111(8):1466-1476. [doi: 10.1111/add.13342] [Medline: 26857917]

65. Seto E, Hua J, Wu L, Shia V, Eom S, Wang M, et al. Models of individual dietary behavior based on smartphone data: the influence of routine, physical activity, emotion, and food environment. PLoS One 2016;11(4):e0153085 [FREE Full text] [doi: 10.1371/journal.pone.0153085] [Medline: 27049852]

66. Setodji CM, Martino SC, Scharf DM, Shadel WG. Quantifying the persistence of pro-smoking media effects on college students' smoking risk. J Adolesc Health 2014 Apr;54(4):474-480 [FREE Full text] [doi: 10.1016/j.jadohealth.2013.09.011] [Medline: 24268361]

67. Shiffman S, Balabanis MH, Gwaltney CJ, Paty JA, Gnys M, Kassel JD, et al. Prediction of lapse from associations between smoking and situational antecedents assessed by ecological momentary assessment. Drug Alcohol Depend 2007 Dec 1;91(2-3):159-168 [FREE Full text] [doi: 10.1016/j.drugalcdep.2007.05.017] [Medline: 17628353] 
68. Simons JS, Emery NN, Simons RM, Wills TA, Webb MK. Effects of alcohol, rumination, and gender on the time course of negative affect. Cogn Emot 2017 Nov;31(7):1405-1418 [FREE Full text] [doi: 10.1080/02699931.2016.1226162] [Medline: 27609298]

69. Spook JE, Paulussen T, Kok G, Van EP. Monitoring dietary intake and physical activity electronically: feasibility, usability, and ecological validity of a mobile-based Ecological Momentary Assessment tool. J Med Internet Res 2013;15(9):e214 [FREE Full text] [doi: 10.2196/jmir.2617] [Medline: 24067298]

70. Thielsch C, Andor T, Ehring T. Do metacognitions and intolerance of uncertainty predict worry in everyday life? An ecological momentary assessment study. Behav Ther 2015 Jul;46(4):532-543. [doi: 10.1016/j.beth.2015.05.001] [Medline: 26163716]

71. Tiplady B, Oshinowo B, Thomson J, Drummond GB. Alcohol and cognitive function: assessment in everyday life and laboratory settings using mobile phones. Alcohol Clin Exp Res 2009 Dec;33(12):2094-2102. [doi:

10.1111/j.1530-0277.2009.01049.x] [Medline: 19740132]

72. Waters AJ, Szeto EH, Wetter DW, Cinciripini PM, Robinson JD, Li Y. Cognition and craving during smoking cessation: an ecological momentary assessment study. Nicotine Tob Res 2014 May;16 Suppl 2:S111-S118 [FREE Full text] [doi: 10.1093/ntr/ntt108] [Medline: 23901053]

73. Witkiewitz K, Desai SA, Steckler G, Jackson KM, Bowen S, Leigh BC, et al. Concurrent drinking and smoking among college students: an event-level analysis. Psychol Addict Behav 2012 Sep;26(3):649-654 [FREE Full text] [doi: 10.1037/a0025363] [Medline: 21895348]

74. Zenk SN, Horoi I, McDonald A, Corte C, Riley B, Odoms-Young AM. Ecological momentary assessment of environmental and personal factors and snack food intake in African American women. Appetite 2014 Dec;83:333-341. [doi: 10.1016/j.appet.2014.09.008] [Medline: 25239402]

75. Aaron LA, Turner JA, Mancl LA, Sawchuk CN, Huggins KH, Truelove EL. Daily pain coping among patients with chronic temporomandibular disorder pain: an electronic diary study. J Orofac Pain 2006;20(2):125-137. [Medline: 16708830]

76. Dewey D, McDonald MK, Brown WJ, Boyd SJ, Bunnell BE, Schuldberg D. The impact of ecological momentary assessment on posttraumatic stress symptom trajectory. Psychiatry Res 2015 Dec 15;230(2):300-303. [doi: 10.1016/j.psychres.2015.09.009] [Medline: 26381184]

77. Dhingra LK, Homel P, Grossman B, Chen J, Scharaga E, Calamita S, et al. Ecological momentary assessment of smoking behavior in persistent pain patients. Clin J Pain 2014 Mar;30(3):205-213. [doi: 10.1097/AJP.0b013e31829821c7] [Medline: 23689351]

78. Epstein DH, Tyburski M, Craig IM, Phillips KA, Jobes ML, Vahabzadeh M, et al. Real-time tracking of neighborhood surroundings and mood in urban drug misusers: application of a new method to study behavior in its geographical context. Drug Alcohol Depend 2014 Jan 1;134:22-29 [FREE Full text] [doi: 10.1016/j.drugalcdep.2013.09.007] [Medline: 24332365]

79. Fitzsimmons-Craft EE, Accurso EC, Ciao AC, Crosby RD, Cao L, Pisetsky EM, et al. Restrictive eating in anorexia nervosa: examining maintenance and consequences in the natural environment. Int J Eat Disord 2015 Nov;48(7):923-931 [FREE Full text] [doi: 10.1002/eat.22439] [Medline: 26310991]

80. Hachizuka M, Yoshiuchi K, Yamamoto Y, Iwase S, Nakagawa K, Kawagoe K, et al. Development of a personal digital assistant (PDA) system to collect symptom information from home hospice patients. J Palliat Med 2010 Jun;13(6):647-651. [doi: 10.1089/jpm.2009.0350] [Medline: 20509795]

81. Juengst SB, Graham KM, Pulantara IW, McCue M, Whyte EM, Dicianno BE, et al. Pilot feasibility of an mHealth system for conducting ecological momentary assessment of mood-related symptoms following traumatic brain injury. Brain Inj 2015 Aug;29(11):1351-1361. [doi: 10.3109/02699052.2015.1045031] [Medline: 26287756]

82. Kulich K, Keininger DL, Tiplady B, Banerji D. Symptoms and impact of COPD assessed by an electronic diary in patients with moderate-to-severe COPD: psychometric results from the SHINE study. Int J Chron Obstruct Pulmon Dis 2015;10:79-94 [FREE Full text] [doi: 10.2147/COPD.S73092] [Medline: 25609942]

83. Kuroi R, Minakuchi H, Hara ES, Kawakami A, Maekawa K, Okada H, et al. A risk factor analysis of accumulated postoperative pain and swelling sensation after dental implant surgery using a cellular phone-based real-time assessment. J Prosthodont Res 2015 Jul;59(3):194-198. [doi: 10.1016/j.jpor.2015.05.003] [Medline: 26077378]

84. Lavender JM, De Young KP, Wonderlich SA, Crosby RD, Engel SG, Mitchell JE, et al. Daily patterns of anxiety in anorexia nervosa: associations with eating disorder behaviors in the natural environment. J Abnorm Psychol 2013 Aug;122(3):672-683 [FREE Full text] [doi: 10.1037/a0031823] [Medline: 23647124]

85. Merwin RM, Dmitrieva NO, Honeycutt LK, Moskovich AA, Lane JD, Zucker NL, et al. Momentary predictors of insulin restriction among adults with type 1 diabetes and eating disorder symptomatology. Diabetes Care 2015 Nov;38(11):2025-2032 [FREE Full text] [doi: 10.2337/dc15-0753] [Medline: 26384389]

86. Munsch S, Meyer AH, Milenkovic N, Schlup B, Margraf J, Wilhelm FH. Ecological momentary assessment to evaluate cognitive-behavioral treatment for binge eating disorder. Int J Eat Disord 2009 Nov;42(7):648-657. [doi: 10.1002/eat.20657] [Medline: 19197978 ]

87. Okifuji A, Bradshaw DH, Donaldson GW, Turk DC. Sequential analyses of daily symptoms in women with fibromyalgia syndrome. J Pain 2011 Jan;12(1):84-93 [FREE Full text] [doi: 10.1016/j.jpain.2010.05.003] [Medline: 20591745] 
88. Sohl SJ, Friedberg F. Memory for fatigue in chronic fatigue syndrome: relationships to fatigue variability, catastrophizing, and negative affect. Behav Med 2008;34(1):29-38 [FREE Full text] [doi: 10.3200/BMED.34.1.29-38] [Medline: 18400687]

89. Thielsch C, Ehring T, Nestler S, Wolters J, Kopei I, Rist F, et al. Metacognitions, worry and sleep in everyday life: studying bidirectional pathways using Ecological Momentary Assessment in GAD patients. J Anxiety Disord 2015 Jun;33:53-61. [doi: 10.1016/j.janxdis.2015.04.007] [Medline: 26005837]

90. Weaver A, Young AM, Rowntree J, Townsend N, Pearson S, Smith J, et al. Application of mobile phone technology for managing chemotherapy-associated side-effects. Ann Oncol 2007 Nov;18(11):1887-1892 [FREE Full text] [doi: 10.1093/annonc/mdm354] [Medline: 17921245]

91. Asselbergs J, Ruwaard J, Ejdys M, Schrader N, Sijbrandij M, Riper H. Mobile phone-based unobtrusive ecological momentary assessment of day-to-day mood: an explorative study. J Med Internet Res 2016 Mar 29;18(3):e72 [FREE Full text] [doi: 10.2196/jmir.5505] [Medline: 27025287]

92. Dunbar MS, Scharf D, Kirchner T, Shiffman S. Do smokers crave cigarettes in some smoking situations more than others? Situational correlates of craving when smoking. Nicotine Tob Res 2010 Mar;12(3):226-234 [FREE Full text] [doi: 10.1093/ntr/ntp198] [Medline: 20133379]

93. Hofmann W, Adriaanse M, Vohs KD, Baumeister RF. Dieting and the self-control of eating in everyday environments: an experience sampling study. Br J Health Psychol 2014 Sep;19(3):523-539 [FREE Full text] [doi: 10.1111/bjhp.12053] [Medline: 23751109]

94. Hughes CD, Gunthert K, Wenze S, German R. The subscale specificity of the Affective Control Scale: Ecological validity and predictive validity of feared emotions. Motiv Emot 2015 Jun 5;39(6):984-992. [doi: 10.1007/s11031-015-9497-7]

95. Huguet A, McGrath PJ, Wheaton M, Mackinnon SP, Rozario S, Tougas ME, et al. Testing the feasibility and psychometric properties of a mobile diary (myWHI) in adolescents and young adults with headaches. JMIR Mhealth Uhealth 2015 May 08;3(2):e39 [FREE Full text] [doi: 10.2196/mhealth.3879] [Medline: 25956377]

96. Kanning M, Hansen S. Need satisfaction moderates the association between physical activity and affective states in adults aged 50+: an activity-triggered ambulatory assessment. Ann Behav Med 2017 Feb;51(1):18-29 [FREE Full text] [doi: 10.1007/s12160-016-9824-6] [Medline: 27539030]

97. Kashdan TB, Farmer AS. Differentiating emotions across contexts: comparing adults with and without social anxiety disorder using random, social interaction, and daily experience sampling. Emotion 2014 Jun;14(3):629-638 [FREE Full text] [doi: 10.1037/a0035796] [Medline: 24512246]

98. Kwapil TR, Barrantes-Vidal N, Armistead MS, Hope GA, Brown LH, Silvia PJ, et al. The expression of bipolar spectrum psychopathology in daily life. J Affect Disord 2011 Apr;130(1-2):166-170 [FREE Full text] [doi: 10.1016/j.jad.2010.10.025] [Medline: 21056476]

99. Schüz B, Bower J, Ferguson SG. Stimulus control and affect in dietary behaviours. An intensive longitudinal study. Appetite 2015 Apr;87:310-317. [doi: 10.1016/j.appet.2015.01.002] [Medline: 25579222]

100. Schüz N, Walters JAE, Frandsen M, Bower J, Ferguson SG. Compliance with an EMA monitoring protocol and its relationship with participant and smoking characteristics. Nicotine Tob Res 2014 May;16(Suppl 2):S88-S92. [doi: 10.1093/ntr/ntt142] [Medline: 24052500]

101. Schwerdtfeger A, Eberhardt R, Chmitorz A, Schaller E. Momentary affect predicts bodily movement in daily life: an ambulatory monitoring study. J Sport Exerc Psychol 2010 Oct;32(5):674-693. [Medline: 20980710]

102. Warthen MW, Tiffany ST. Evaluation of cue reactivity in the natural environment of smokers using ecological momentary assessment. Exp Clin Psychopharmacol 2009 Apr;17(2):70-77 [FREE Full text] [doi: 10.1037/a0015617] [Medline: 19331483]

103. Vasconcelos E Sa D, Wearden A, Hartley S, Emsley R, Barrowclough C. Expressed Emotion and behaviourally controlling interactions in the daily life of dyads experiencing psychosis. Psychiatry Res 2016 Nov 30;245:406-413. [doi: 10.1016/j.psychres.2016.08.060] [Medline: 27611070]

104. Ebner-Priemer UW, Kuo J, Schlotz W, Kleindienst N, Rosenthal MZ, Detterer L, et al. Distress and affective dysregulation in patients with borderline personality disorder: a psychophysiological ambulatory monitoring study. J Nerv Ment Dis 2008 Apr;196(4):314-320. [doi: 10.1097/NMD.0b013e31816a493f] [Medline: 18414126]

105. Green KT, Dennis PA, Neal LC, Hobkirk AL, Hicks TA, Watkins LL, et al. Exploring the relationship between posttraumatic stress disorder symptoms and momentary heart rate variability. J Psychosom Res 2016 Mar;82:31-34 [FREE Full text] [doi: 10.1016/j.jpsychores.2016.01.003] [Medline: 26944396]

106. Mazure CM, Weinberger AH, Pittman B, Sibon I, Swendsen J. Gender and stress in predicting depressive symptoms following stroke. Cerebrovasc Dis 2014;38(4):240-246 [FREE Full text] [doi: 10.1159/000365838] [Medline: 25401293]

107. Kothari DJ, Davis MC, Yeung EW, Tennen HA. Positive affect and pain: mediators of the within-day relation linking sleep quality to activity interference in fibromyalgia. Pain 2015 Mar;156(3):540-546 [FREE Full text] [doi: 10.1097/01.j.pain.0000460324.18138.0a] [Medline: 25679472]

108. Burns JW, Gerhart JI, Bruehl S, Peterson KM, Smith DA, Porter LS, et al. Anger arousal and behavioral anger regulation in everyday life among patients with chronic low back pain: Relationships to patient pain and function. Health Psychol 2015 May;34(5):547-555 [FREE Full text] [doi: 10.1037/hea0000091] [Medline: 25110843] 
109. Smyth JM, Wonderlich SA, Heron KE, Sliwinski MJ, Crosby RD, Mitchell JE, et al. Daily and momentary mood and stress are associated with binge eating and vomiting in bulimia nervosa patients in the natural environment. J Consult Clin Psychol 2007 Aug;75(4):629-638. [doi: 10.1037/0022-006X.75.4.629] [Medline: 17663616]

110. Ainsworth J, Palmier-Claus JE, Machin M, Barrowclough C, Dunn G, Rogers A, et al. A comparison of two delivery modalities of a mobile phone-based assessment for serious mental illness: native smartphone application vs text-messaging only implementations. J Med Internet Res 2013;15(4):e60 [FREE Full text] [doi: 10.2196/jmir.2328] [Medline: 23563184]

111. Tomiyama AJ, Mann T, Comer L. Triggers of eating in everyday life. Appetite 2009 Feb;52(1):72-82 [FREE Full text] [doi: 10.1016/j.appet.2008.08.002] [Medline: 18773931]

112. Luczak SE, Rosen IG, Wall TL. Development of a real-time repeated-measures assessment protocol to capture change over the course of a drinking episode. Alcohol Alcohol 2015 Mar;50(2):180-187 [FREE Full text] [doi: 10.1093/alcalc/agu100] [Medline: 25568142]

113. Monk RL, Heim D, Qureshi A, Price A. 'I have no clue what I drunk last night' using Smartphone technology to compare in-vivo and retrospective self-reports of alcohol consumption. PLoS One 2015;10(5):e0126209 [FREE Full text] [doi: 10.1371/journal.pone.0126209] [Medline: 25992573]

114. Santangelo P, Reinhard I, Mussgay L, Steil R, Sawitzki G, Klein C, et al. Specificity of affective instability in patients with borderline personality disorder compared to posttraumatic stress disorder, bulimia nervosa, and healthy controls. J Abnorm Psychol 2014 Feb;123(1):258-272 [FREE Full text] [doi: 10.1037/a0035619] [Medline: 24661176]

115. Piasecki TM, Cooper ML, Wood PK, Sher KJ, Shiffman S, Heath AC. Dispositional drinking motives: associations with appraised alcohol effects and alcohol consumption in an ecological momentary assessment investigation. Psychol Assess 2014 Jun;26(2):363-369 [FREE Full text] [doi: 10.1037/a0035153] [Medline: 24274049]

116. Goldschmidt AB, Wonderlich SA, Crosby RD, Engel SG, Lavender JM, Peterson CB, et al. Ecological momentary assessment of stressful events and negative affect in bulimia nervosa. J Consult Clin Psychol 2014 Feb;82(1):30-39 [FREE Full text] [doi: 10.1037/a0034974] [Medline: 24219182]

117. Trela CJ, Piasecki TM, Bartholow BD, Heath AC, Sher KJ. The natural expression of individual differences in self-reported level of response to alcohol during ecologically assessed drinking episodes. Psychopharmacology (Berl) 2016 Jun;233(11):2185-2195 [FREE Full text] [doi: 10.1007/s00213-016-4270-5] [Medline: 27037938]

118. Tomko RL, Solhan MB, Carpenter RW, Brown WC, Jahng S, Wood PK, et al. Measuring impulsivity in daily life: the momentary impulsivity scale. Psychol Assess 2014 Jun;26(2):339-349 [FREE Full text] [doi: 10.1037/a0035083] [Medline: 24274047]

119. Ono M, Schneider S, Junghaenel DU, Stone AA. What affects the completion of ecological momentary assessments in chronic pain research? An individual patient data meta-analysis. J Med Internet Res 2019 Feb 05;21(2):e11398 [FREE Full text] [doi: 10.2196/11398] [Medline: $\underline{\text { 30720437] }}$

120. Morris ZS, Wooding S, Grant J. The answer is 17 years, what is the question: understanding time lags in translational research. J R Soc Med 2011 Dec;104(12):510-520 [FREE Full text] [doi: 10.1258/jrsm.2011.110180] [Medline: 22179294]

121. Khangura S, Konnyu K, Cushman R, Grimshaw J, Moher D. Evidence summaries: the evolution of a rapid review approach. Syst Rev 2012;1:10 [FREE Full text] [doi: 10.1186/2046-4053-1-10] [Medline: 22587960]

122. Elkins MR. Updating systematic reviews. J Physiother 2018 Jan;64(1):1-3 [FREE Full text] [doi: 10.1016/j.jphys.2017.11.009] [Medline: 29289593]

\author{
Abbreviations \\ EMA: ecological momentary assessment \\ ES: effect size \\ ESS: effective sample size \\ mEMA: mobile ecological momentary assessment \\ mEMI: mobile ecological momentary intervention
}

Edited by G Eysenbach; submitted 12.11.19; peer-reviewed by M May, G Dunton, K Heron; comments to author 23.12.19; revised
version received 01.03.20; accepted 31.10.20; published 03.03.21
Please cite as:
Williams MT, Lewthwaite H, Fraysse F, Gajewska A, Ignatavicius J, Ferrar K
Compliance With Mobile Ecological Momentary Assessment of Self-Reported Health-Related Behaviors and Psychological Constructs
in Adults: Systematic Review and Meta-analysis
J Med Internet Res $2021 ; 23(3):$ : 17023
URL: https://www.jmir.org/2021/3/e17023
doi: $10.2196 / 17023$
PMID: $\underline{3656451}$


CMarie T Williams, Hayley Lewthwaite, François Fraysse, Alexandra Gajewska, Jordan Ignatavicius, Katia Ferrar. Originally published in the Journal of Medical Internet Research (http://www.jmir.org), 03.03.2021. This is an open-access article distributed under the terms of the Creative Commons Attribution License (https://creativecommons.org/licenses/by/4.0/), which permits unrestricted use, distribution, and reproduction in any medium, provided the original work, first published in the Journal of Medical Internet Research, is properly cited. The complete bibliographic information, a link to the original publication on http://www.jmir.org/, as well as this copyright and license information must be included. 